\title{
MOTIVOS À PRÁTICA NO ESPORTE ESCOLAR EM ADOLESCENTES
}

\section{REASONS TO PRACTICE IN SCHOOL SPORT IN ADOLESCENTS}

\author{
João Paulo dos PASSOS-SANTOS ${ }^{1}$
}

Cassiano Ricardo $\mathrm{RECH}^{2}$

\begin{abstract}
Resumo: o objetivo desse estudo foi analisar os motivos à competitividade no esporte em adolescentes, de acordo com o gênero, tipo de esporte e condição econômica. Realizou-se um estudo descritivo com adolescentes (13-17 anos) praticantes de atividades esportivas. Participaram 142 adolescentes. Os Motivos à Competitividade no Esporte foram divididos em três dimensões, sendo Orientada à Vitória $(\mathrm{OV})$, Orientada à Performance $(\mathrm{OP})$ e Orientada ao Status (OS), a soma das respostas a estas questões indicam o nível de Competitividade em Jovens (CJ). Foram utilizados os softwares Microsoft Excel e Assitat v. 7.6 Beta, por meio dos testes Mann-Whitney ou teste U e Kruskal-Wallis, com o nível de significância de p < 0,05. A média da OP 4,74 (dp = 0,62) foi a mais elevada dentre as dimensões, seguida da OV 4,15 (dp $=0,88)$ e OS 3,32 (dp =1,06), por final a CJ obteve o valor de 4,27 $(\mathrm{dp}=0,82)$, revelando uma boa motivação para a prática esportiva. Somente foi identificada diferença estatisticamente significativa dentre os sexos na OS e na CJ, demonstrando que os rapazes são mais motivados a prática de esportes do que as moças. Não foram observadas diferenças significativas dentre o tipo de modalidade (individual ou coletiva) em nenhuma das dimensões ( $p>0,05)$. Também não foram observadas diferenças significativas dentre as classes econômicas, porém, os indivíduos contidos nas classes B2 e C apresentaram médias mais elevadas que os da A e B1. Conclui-se que, os motivos que mais levam os adolescentes a competirem estão ligados ao desempenho e de forma contrária ao status. As moças são menos motivadas que rapazes para a prática. O tipo de modalidade se individual ou coletiva e classe econômica, não influenciam nos motivos à competitividade.
\end{abstract}

Palavras-chave: Adolescentes. Motivação. Esportes.

Abstract: the objective of this study was to analyze the reasons of competitiveness in adolescent athletes in the sport of Ponta Grossa - Parana. We conducted a descriptive study. The population consisted of adolescents aged between 13 and 17 years of practicing sports, however, the sample consisted of 142 people. Were used during data collection sociodemographic questionnaire and Reasons for competitiveness in sports, divided into three dimensions and was being Oriented to Victoria (OV), Oriented to Performance (OP) and Oriented to Status (OS), the sum of the answers to these questions indicate the level of Competitiveness in Young (CY). We used the software Microsoft Excel and the program Assitat 7.6 Beta, by means tests Mann-Whitney U test and Kruskal-Wallis test, with

\footnotetext{
${ }^{1}$ Professor da Secretaria de Estado da Educação do Paraná. Mestre em Educação pela Universidade Estadual de Maringá (UEM). E-mail: jopa_passos@ hotmail.com

${ }^{2}$ Professor do Programa de Pós-Graduação em Educação Física da Universidade Federal de Santa Catarina (UFSC). E-mail: crrech@ hotmail.com
} 


\section{HORIZONTES - REVISTA DE EDUCACÃ̃O}

significance level set for the analysis of $\mathrm{p}<0.05$. The results show that OP $4.74(\mathrm{sd}=0.62)$ was more prevalent among the dimensions, followed by OV $4.15(\mathrm{sd}=0.88)$ and OS $3.32(\mathrm{sd}=$ 1.06), to $\mathrm{CY}$ was found value of 4.27 ( $\mathrm{sd}=0.82)$, revealing a good motivation for the sport. Was noted statistically significant difference $(\mathrm{p}<0.01)$ among the sexes, showing that boys are more motivated to practice sports than girls. There were no significant differences among the type of modality, individually or collectively in any dimension ( $p>0,05)$. There were also no significant differences among the economic classes, however, individuals contained in class B2 and $\mathrm{C}$ presenting higher averages than those of $\mathrm{A}$ and $\mathrm{B} 1$. It is concluded that motivates teenagers to compete is focused on the performance and acquisition of new skills. The girls are less motivated than men to practice. The type of modality and social class did not influence the competitiveness reasons.

Keywords: Adolescents. Motivation. Sports.

\section{Introdução}

O adolescente, de acordo com o Estatuto da Criança e Adolescente (ECA) (BRASIL, 2016), é considerado aquele indivíduo com idade compreendida dentre 12 e 18 anos. Sendo entendida como obrigação da família, comunidade, sociedade e do poder público, garantir com integral preferência a concretização dos direitos pertinente à vida, saúde, alimentação, educação, esporte, lazer, profissionalização, cultura, dignidade, respeito, liberdade, convivência familiar e comunitária (BRASIL, 2016).

O período da adolescência é uma época de transição entre a infância e a fase adulta, motivando políticas localizadas no preparado para o mundo adulto. Por excelência a "Educação" torna-se a maior articulação, e como formas de complementação do tempo escolar poderão estar inseridas em programas dirigidos ao uso do "tempo livre", por meio de prática esportiva e lazer, para garantir uma formação sadia dos jovens. Nessa perspectiva, o adolescente depara-se com possíveis ameaças de ordem social, ou déficits nas manifestações de seu desenvolvimento pleno. Emergem, então, indagações advindas de comportamentos de risco e transgressão. Os setores que devem desenvolver ações sob tal problematização são os de saúde, justiça e segurança social, (gravidez precoce, drogas, violência, criminalidade e narcotráfico) (ABRAMO, 2006; WATARAI; ROMANELLI, 2005).

Posicionando a prática esportiva como de grande importância na fase da adolescência para o ser humano, motivá-lo a esse segmento torna-se imprescindível. Desse modo, de acordo com Cratty (1984), a questão de motivar demonstra os fatores e processos que levam o 


\section{HORIZONTES - REVISTA DE EDUCAÇÃO}

indivíduo a certa ação. Investigar os motivos implica na análise das razões pelas quais se pretende realizar algo ou executar algumas tarefas com maior empenho que outras, ou até persistir em uma atividade por mais tempo.

Para Lopes e Nunomura (2007), averiguar os fatores motivacionais que induzem jovens à prática esportiva auxilia o direcionamento das metas para o atleta que escolherá pelo alto nível. Ainda, colabora para a preparação das atividades direcionadas aos treinamentos e das relativas estratégias as quais objetivam evitar o abandono precoce do esporte.

Da mesma forma, não existem dificuldades em selecionar indicadores das inúmeras vantagens de adolescentes ativos. No entanto, níveis comprometedores da prática de atividades físicas nessas idades possivelmente os introduzirão a grandes limitantes biológicos e psicoemocionais cogitados para a idade adulta, influenciando assim a qualidade de vida futura (GUEDES; GUEDES, 2006).

Estudo de Paim (2001), realizado na cidade de Maringá - PR, contando com 32 indivíduos, cujas idades compreendiam entre 10 e 16 anos, encontrou em ambos os sexos que o principal objetivo que leva os jovens a praticarem o esporte está ligado a fatores motivacionais para desenvolver habilidades.

Interdonado et al. (2008) avaliaram 87 atletas com idade média de 12 e14 anos, tiveram como resultado o fato de associarem a questão da saúde como o principal objetivo a prática esportiva, em contrapartida o fato de "encontrar amigos" e "emagrecer" pouco os motiva.

Os motivos que os indivíduos desempenham ao praticar atividades esportivas podem mudar à medida que eles envelhecem, sendo característico à criança, de forma externa, o ganho de premiações, daqueles que ingressam em esportes altamente competitivos e, mais tarde, da mesma forma aos motivos intrínsecos de atletas profissionais muito bem remunerados ou de simples amadores (CRATTY, 1984).

Ao qualificar alguém como competitivo o que se quer dizer é que o atleta em questão é um indivíduo com alto nível dessa característica em sua personalidade (a competitividade), da mesma forma e intensidade, em três possíveis direções: 1) Orientada à Vitória, que seria como forma de aparecimento de aspectos (positivos e negativos) relacionados a resultados, ou seja, as vitórias e derrotas; 2) Orientada à Performance, no sentido da busca do desenvolvimento da mesma; 3) Orientação ao Status, como uma obtenção de prestígio social (Status), a partir do sucesso obtido nas competições esportivas de um modo geral (BALBINOTTI et al., 2011). 


\section{HORIZONTES - REVISTA DE EDUCAÇÃO}

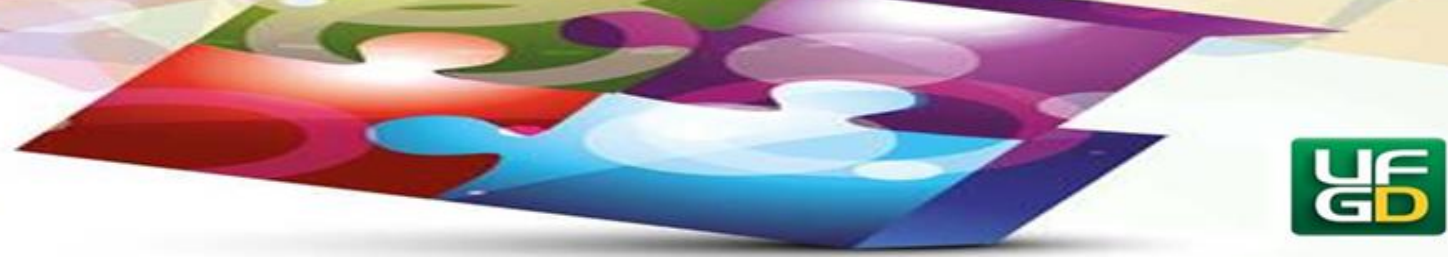

A atividade esportiva na infância e adolescência figura-se como de grande importância, uma vez que auxilia no processo educacional de formação do cidadão, além de outros inúmeros benefícios como condicionamento físico (saúde), possibilidade de seguir carreira em determinada modalidade, dentre outras. Porém, a fase antecedente a adulta, é aquela onde o adolescente mais compete, e é nela em que o futuro do provável esportista toma sua problemática, e muitas vezes, ocorre a desistência, por vários fatores, em algumas vezes até a utilização de produtos ilícitos, também como a realização de outras atividades não saudáveis, sabendo disso, investigar os fatores que os motivam no esporte contribuí para estudiosos e técnicos desportivos delinearem formas de diminuir o abandono e melhorar o desempenho de acordo com os interesses frente aquela prática. Dessa forma, o estudo buscou analisar os motivos à competitividade no esporte em atletas adolescentes, segundo o sexo, modalidade e classificação econômica.

\section{Metodologia}

Foi realizado um estudo descritivo do tipo transversal, que tem por objetivo analisar fatos sem interferência direta neles (THOMAS; NELSON, 2002). Tal pesquisa é transversal no sentido que pondera os resultados encontrados nas variáveis em um único momento.

A população foi constituída por adolescentes com idades entre 13 e 17 anos praticantes de atividades esportivas de Ponta Grossa - Paraná, nos locais de treinamentos das próprias instituições de ensino pesquisadas, antes que se iniciassem as atividades diárias. Fizeram parte da amostra 142 pessoas, de duas escolas públicas e três privadas.

Durante a coleta de dados foi utilizado o Questionário sócio-demográfico, o qual avaliou aspectos característicos sobre os pesquisados como sexo, idade, escola, tempo de treinamento e modalidade praticada. Questionário de Classificação Econômica, da Associação Brasileira de Empresas de Pesquisas (ABEP, 2011), em que o Critério de Classificação Econômica Brasil, enfatiza sua função de estimar o poder de compra das pessoas e famílias urbanas, abandonando a pretensão de classificar a população em termos de "classes sociais". E a Escala Balbinotti de Motivos à Competitividade no Esporte (EBMCE-18): Instrumento validado para utilização em jovens por Balbinotti et al. (2011), em que possui 18 questões formuladas positivamente, divididas em 3 dimensões, contendo 6 perguntas cada. 


\section{HORIZONTES - REVISTA DE EDUCAÇÃO}

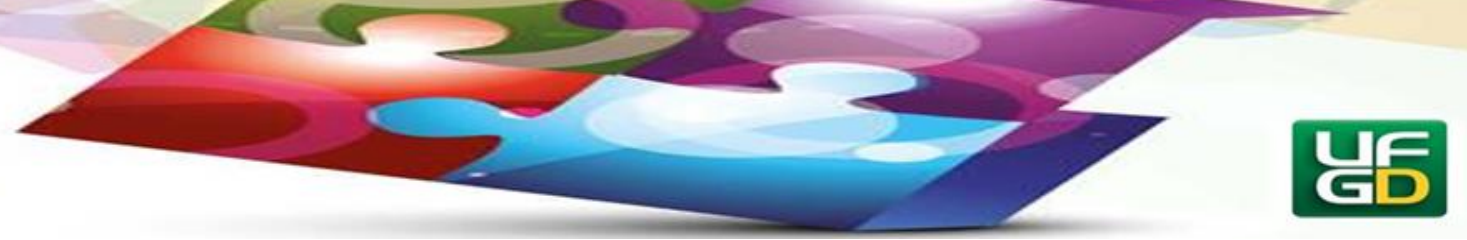

A dimensão Orientada à Vitória (OV), é entendida como o desejo de ser campeão no esporte, aquela Orientada à Performance (OP), que poderia ser representada pela vontade de desenvolver suas próprias habilidades e, finalmente, aquela Orientada ao Status (OS), característica pela possibilidade de ganhar dinheiro, prestígio e reconhecimento social, todas por meio da utilização da escala do tipo Likert, sendo o mínimo 1 e o máximo 5 pontos. $\mathrm{O}$ somatório das respostas a essas questões indica o nível da variável (ou dimensão) Competitividade em Jovens (CJ). Para avaliar os comportamentos de resposta dos sujeitos, a escala foi graduada em até 5 pontos, iniciada em "isso me motiva pouquíssimo" (1), seguida por "isso me motiva pouco", "isso me motiva", "isso me motiva muito" e "isso me motiva muitíssimo", respectivamente representadas por (2), (3), (4) e (5) pontos.

Inicialmente, os estabelecimentos de ensino responsáveis foram contatados para que fossem explicados os objetivos do respectivo estudo, sendo pesquisado nesse momento o número de equipes e alunos/atletas participantes. Logo que houve a liberação dos responsáveis pelos estabelecimentos, então, foi enviado o projeto à Comissão de Ética em Pesquisa envolvendo Seres Humanos (COEP) da Universidade Estadual de Ponta Grossa (UEPG) e aprovado com o Parecer $n^{\circ}$ 119/2011, após, foram enviados aos pais ou responsáveis os Termos de Consentimento, Livre e Esclarecido (TCLE), quando houve a resposta, foi iniciada a coleta de dados junto aos adolescentes nos locais de treinamentos.

Os pesquisados responderam aos questionários em pequenos grupos divididos por modalidades e, na presença dos pesquisadores, onde os mesmos explicavam os procedimentos e prestavam auxílio, caso fosse necessário, buscando a maior fidedignidade quanto às informações, em seguida os adolescentes podiam voltar às atividades diárias.

Foi utilizada uma amostra não intencional, por ser um grupo específico em que houve acesso imediato. Os dados foram analisados inicialmente por meio do programa Microsoft Excel 2010 e apresentados em tabelas, utilizando nesse momento a estatística descritiva simples, com frequência, percentual, média e desvio padrão (dp). Já para a comparação e relação entre grupos e variáveis, foi adotado o software Assitat v. 7.6 Beta (2011), a princípio os resultados foram ponderados pelo teste de normalidade Shapiro-Wilk, sendo detectados valores diferentes da curva normal ( $\mathrm{p}<0,01$ ), então se utilizou os testes Mann-Whitney ou teste U para duas amostras não-paramétricas e o teste de Kruskal-Wallis quando o número de variáveis era maior. O nível de significância estipulado para as análises foi de $\mathrm{p}<0,05$. 


\section{Resultados e Discussão}

A Tabela 1 apresenta os resultados das características sócio-demográficas e de competitividade nos adolescentes. Observa-se que houve uma predominância do sexo masculino (59,86\%). A média de idade e tempo de treinamento foram 14,25 (dp =1,19) e 3,32 $(\mathrm{dp}=3,0)$ anos, respectivamente. Observou-se, ainda, que a classe econômica predominante foi a "B2" onde se enquadraram 39,4\% dos pesquisados, seguida por $26,7 \%, 14,8 \%, 11,9 \%, 7,0 \%$ e $0,7 \%$, concomitantemente $\mathrm{B} 1, \mathrm{~A} 2, \mathrm{C} 1, \mathrm{C} 2$ e $\mathrm{A} 1$, nenhum dos adolescentes pertencem às classes D e E. De forma geral a competitividade no esporte foi mais presente na Orientação à Performance $(\mathrm{OP})$ 4,74 (dp = 0,62), não sendo observada diferença significativa entre as variáveis. A Competitividade em Jovens (CJ) obteve o valor de 4,27 (dp =0,82), revelando uma motivação satisfatória à prática esportiva.

Tabela 1: Classificação econômica e competitividade em atletas adolescentes de cinco escolas de Ponta Grossa, PR, 2011

Classificação econômica (\%)

Motivos à competitividade

No Esporte (Escore)
A1: $0,7 \%(1)$

A2: $14,08 \%(20)$

B1: $26,76 \%$ (38)

B2: $39,44 \%$ (56)

C1: $11,97 \%$ (17)

C2: 7,04\% (10)

OV: 4,15 (dp 0,88)

OP: 4,74 (dp 0,62)

OS: 3,32 (dp 1,06)

CJ: 4,27 (dp 0,82)

$\mathrm{P}<0,05$ para o teste de Kruskal-Wallis na comparação entre os motivos à competitividade. OV: Orientação à Vitória; OP: Orientação à Performance; OS: Orientação ao Status; CP: Competitividade em Jovens. Classificações econômicas (ABEP, 2011): A1, A2, B1, B2, C1 e C2.

Apesar de serem pessoas jovens, nota-se que apresentam certo tempo de prática em esportes, em que se chegou aproximadamente a 6,3 de treinamento, levando em conta o desvio padrão, assim fica mais fácil entender as razões da OP ter apresentado uma média um pouco maior que as outras dimensões, pois esses atletas já demonstram saber a importância da prática de atividade física ao organismo. 


\section{HORIZONTES - REVISTA DE EDUCAÇÃO}

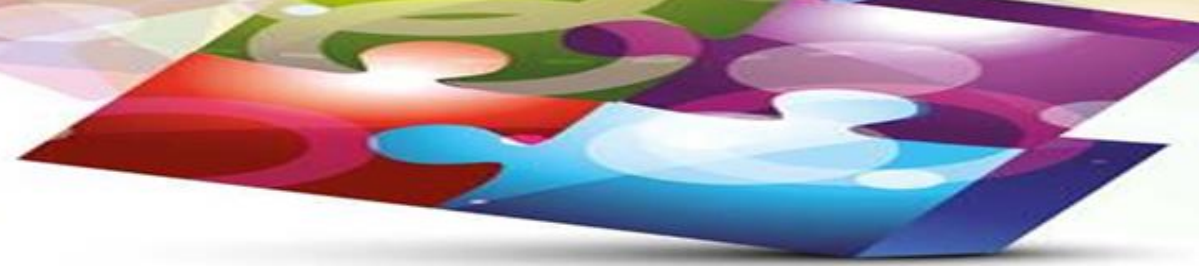

Diante disso, Juchem (2006) estudou 226 jovens tenistas brasileiros com idades entre 13 e 16 anos, divididos em integrantes do ranking (IR) e não integrantes do ranking (NIR). De forma geral, o que mais os motivou à prática de atividades físicas foi o "prazer", seguido por "competitividade" e "saúde", encontrando-se no término das razões a questão do "controle do estresse". A competitividade motivou mais o grupo IR do que os NIR, ainda percebendo que, não estreantes se motivaram mais significativamente do que os estreantes. Entende-se que, para veteranos assim mesmo adolescentes, a competitividade apresenta-se maior, provavelmente pela experiência já adquirida e a aproximação à fase adulta, onde o futuro do atleta encontra a problemática do provável abandono do esporte.

Porém, em relação à prática de esportes como uma forma de atividade física na adolescência, deve-se atentar ao fato do adolescente ainda não ser um adulto, não apresentando as mesmas características para tal feito. Diante da grande popularidade dos esportes juvenis e o provável aumento do condicionamento físico ainda enquanto adolescente, torna-se de grande importância compreender seus processos de crescimento, desenvolvimento e maturação, pois eles ditarão capacidades psicológicas, fisiológicas e desempenho (WILMORE; COSTILL; KENNEY, 2010).

Nesse sentido, entende-se que a motivação à prática da ginástica esportiva de alto nível requer atenção especial, por ser um tipo de esporte que exige do adolescente um grande desempenho físico. Assim, Lopes e Nunomura (2007) buscaram analisar os fatores que motivaram 20 meninas de 11 a 14 anos de São Paulo - SP, a treinarem a ginástica artística em alto nível. Os resultados revelaram que a motivação intrínseca está diretamente relacionada ao gosto pela atividade, à pretensão de se dedicar até o limite físico e ao prazer em treinar após período competitivo vitorioso. Os resultados sugerem que os técnicos devem compreender e considerar os fatores de motivação entre as ginastas de alto nível, visando traçar estratégias que evitem o abandono precoce do esporte, o que parece não ser raro no caso dessa modalidade.

O estudo de Paim (2001) também encontrou como principal meta para a prática esportiva em praticantes de futebol de Maringá-PR, o fato de buscarem adquirir novas habilidades.

Como pode ser observado a CJ, de forma geral é alvo de grande motivação, da mesma forma, a prática esportiva no público infanto-juvenil é um padrão social que faz parte da formação do cidadão na adolescência. Ainda, é constituído em função dos valores sociais e 


\section{HORIZONTES - REVISTA DE EDUCACÃOO}

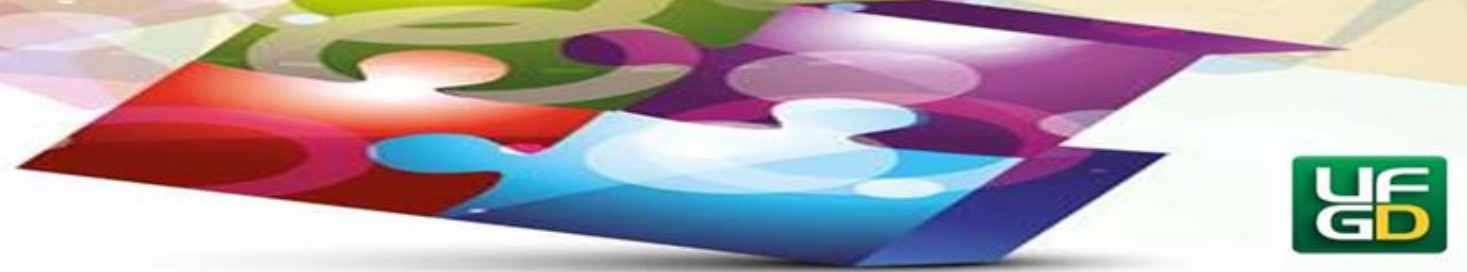

culturais, sendo infalível o estabelecimento de uma ligação entre o esporte, adolescente e o adulto, que envolve paternalismo, emoções e "pressões" das lideranças, como uma condição de "ritual" entre pais e filhos. Percebe-se, assim, que as lideranças adultas podem influir terminantemente no desenvolvimento esportivo em idade escolar (SIMÕES; BÖHME; LUCATO, 1999). Então, o esporte pode ser visto como um veículo entre a formação do caráter e o adolescente, se as políticas públicas caminharem com a grande motivação que essas práticas exercem sobre esse público, problemas característicos dessa faixa etária ainda podem ser solucionados por meio dessas atividades saudáveis, ao invés de ficarem expostos aos fatores de risco que a rua por si só fornece.

A tabela 2 apresenta as dimensões para a competitividade nos indivíduos, onde o sexo masculino obteve média maior, sendo identificada diferença estatisticamente significativa $(\mathrm{p}<$ 0,01) somente na OS, e como era de se esperar na CJ, demonstrando que os rapazes são mais motivados a prática de esportes do que as moças.

\begin{tabular}{lccc}
\hline \multicolumn{4}{c}{ Tabela 2: Motivos à competitividade no esporte de acordo com o sexo } \\
\hline \multicolumn{1}{c}{ Dimensões para a competitividade } & $\begin{array}{c}\text { Masculino } \\
(\mathrm{n}=85)\end{array}$ & $\begin{array}{c}\text { Feminino } \\
(\mathrm{n}=57)\end{array}$ & $\mathrm{P}$ \\
& $(\mathrm{dp})$ & $(\mathrm{dp})$ & \\
\hline Orientada à Vitória & $3,81(0,93)$ & $4,45(0,83)$ & 0,125 \\
Orientada à Performance & $4,3(0,63)$ & $4,7(0,61)$ & 0,235 \\
Orientada ao Status & $3,01(1,11)$ & $3,35(0,98)$ & $\mathbf{0 , 0 0 1 *}$ \\
Competitividade em Jovens & $3,72(0,71)$ & $4,72(0,98)$ & $\mathbf{0 , 0 0 1 *}$ \\
\hline
\end{tabular}

*p $<0,05$ para o teste U. Difere estatisticamente.

Os meninos apresentaram uma maior orientação ao status, tendo em vista que a mesma representa os motivos extrínsecos para a realização, observam-se, de acordo com Samulski (2009), determinantes questões voltadas ao incentivo e as dificuldades de realização de uma tarefa, ou seja, a questão da torcida, problemas ambientais que afetam a prática, ou mesmo o transporte. Destarte, nota-se que geralmente os meninos praticam esportes preocupando-se mais com o reconhecimento futuro, diferindo do pensamento das meninas.

A CJ também apresentou maior significância entre os meninos, assim, percebe-se que eles são mais motivados para a competição no esporte do que as moças. Então, entende-se que os rapazes são altamente motivados, pois se sentem valorizados e competentes para executar as tarefas propostas na competição. As sensações como autoestima, percepção da própria 


\section{HORIZONTES - REVISTA DE EDUCAÇÃO}

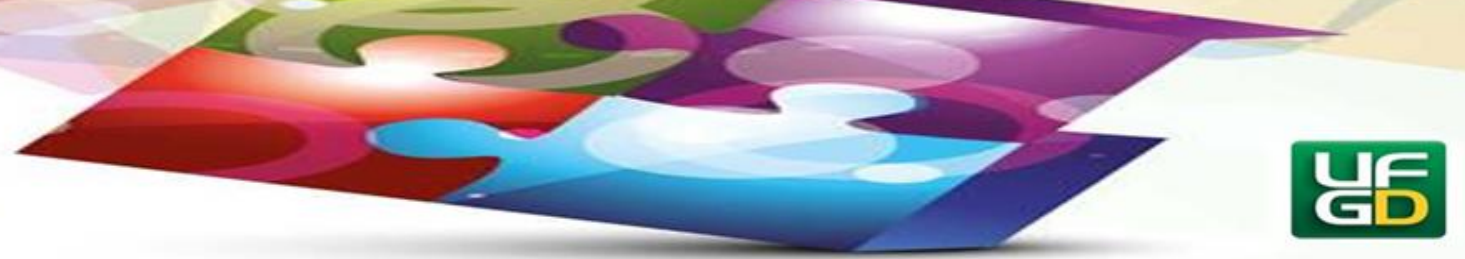

competência e do controle, influenciam na motivação, porém, essas sensações não induzem diretamente o nível de motivação, isso ocorre indiretamente, por meio de estados emocionais produzidos por autopercepções, como por exemplo, a alegria, satisfação, felicidade, orgulho, medo e etc. (SAMULSKI, 2009). Entende-se então que, se sentir capaz e motivado no esporte são os principais fatores que induzem os garotos de um modo geral a competirem.

A participação dos pais na vida esportiva de jovens atletas participantes do esporte escolar foi analisada por Simões, Böhme e Lucato (1999), com 235 escolares de Jundiaí - SP, com idades entre 12 a 14 anos. Não foram encontradas relações estatisticamente significativas das variáveis estudadas entre o papel da mãe e o fato do jovem atleta ser garoto ou garota; já em relação ao papel do pai, verificaram-se influências significativas do mesmo nas variáveis "nível de exigência para a prática esportiva" e "nível de exigência para tornar-se um bom atleta" e o fato do filho ser do sexo masculino ou feminino. Os resultados observados sugerem uma exigência maior do pai em relação ao filho do que à filha, o que leva a crer que os pais incentivam mais os meninos a praticarem esportes do que as meninas, desde pequenos.

Tabela 3: Motivos à competitividade no esporte de acordo com o tipo de esporte

\begin{tabular}{lccc}
\hline \multicolumn{1}{c}{ Dimensões para a competitividade } & $\begin{array}{c}\text { Individual } \\
(33)\end{array}$ & $\begin{array}{c}\text { Coletivo } \\
(109)\end{array}$ & $\mathrm{P}$ \\
& $(\mathrm{dp})$ & $(\mathrm{dp})$ & \\
\hline Orientada à Vitória & $3,93(0,89)$ & $3,98(0,88)$ & 0,895 \\
Orientada à Performance & $4,25(0,59)$ & $4,40(0,62)$ & 0,235 \\
Orientada ao Status & $3,48(1,05)$ & $3,28(1,06)$ & 0,125 \\
Competitividade em Jovens & $3,89(0,66)$ & $3,88(0,71)$ & 0,214 \\
\hline
\end{tabular}

$* \mathrm{p}<0,05$ para o teste de U. Não houve diferença entre os grupos.

O estudo também analisou a competitividade no esporte de acordo com o tipo de modalidade sendo as individuais (atletismo, xadrez, natação, ginástica rítmica e tênis de mesa) e as coletivas (futsal, voleibol, basquetebol e handebol). Em nenhuma das dimensões foi encontrada diferença significativamente estatística (Tabela 3).

Pesquisa de Faria (2004), também comparou modalidades coletivas e individuais em relação à motivação, ele avaliou 448 atletas de 16 a 18 anos participantes dos Jogos Colegiais do Paraná na região noroeste do estado, da mesma forma não houve diferença significativa entre o tipo de esporte praticado. A pesquisa ainda revelou que independentemente da modalidade esportiva o fator intrínseco foi uma ocorrência psicológica que não influenciou na pesquisa. 


\section{HORIZONTES - REVISTA DE EDUCAÇÃO}

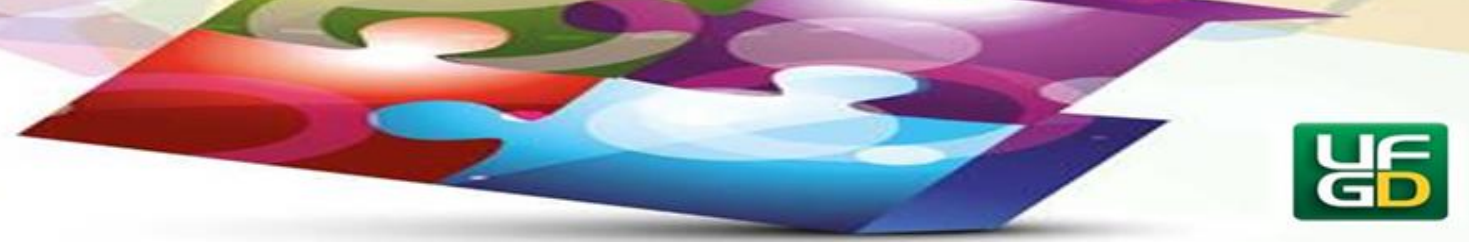

Em contribuição da ABEP (2011), notou-se que algumas classes econômicas não estiveram presentes no estudo, como exemplo a "D" e a "E", e para uma melhor análise as classes A1 e A2 foram agrupadas unicamente como a classe "A" e a C1 e C2 como a "C". Avaliando a dimensão OV observa-se que ela esteve mais presente na classe B2 e menos na A, a $\mathrm{OP}$ foi mais visualizada na $\mathrm{C}$ e de forma contrária também na $\mathrm{A}$, da mesma forma ocorreu na OS, de maneira generalizada a CJ foi mais abrangente na B2, contrapondo-se a A (Tabela 4).

\section{Tabela 4: Motivos à competitividade no esporte de acordo com a classificação econômica}

\begin{tabular}{lcccc}
\hline Classe $(\mathrm{N})$ & \multicolumn{4}{c}{ OV } \\
& $(\mathrm{dp})$ & $\begin{array}{c}\text { OP } \\
(\mathrm{dp})\end{array}$ & $\begin{array}{c}\text { OS } \\
(\mathrm{dp})\end{array}$ & $\begin{array}{c}\text { CJ } \\
(\mathrm{dp})\end{array}$ \\
\hline A (A1 e A2) (21) & $3,28(1,06)$ & $4,11(0,78)$ & $2,35(0,92)$ & $3,24(0,68)$ \\
B1 (38) & $3,87(0,86)$ & $4,31(0,59)$ & $3,32(1,13)$ & $3,82(0,70)$ \\
B2 (56) & $4,30(0,63)$ & $4,48(0,59)$ & $3,53(0,94)$ & $4,11(0,53)$ \\
C (C1 e C2) (27) & $3,94(0,91)$ & $4,40(0,54)$ & $3,69(0,86)$ & $4,04(0,58)$ \\
\hline
\end{tabular}

$* \mathrm{p}<0,05$ para o teste de Kruskal-Wallis. Não houve diferença entre os grupos.

OV: Orientação à Vitória; OP: Orientação à Performance; OS: Orientação ao Status; CP: Competitividade em Jovens. Classificações econômicas (ABEP, 2011): A (A1 e A2), B1, B2 e C (C1 e C2).

Mesmo sem diferença estatística, pode-se observar que de modo geral as classes econômicas menores como a B2 e a C demonstraram de forma global maiores médias em todas as dimensões, além de uma maior motivação à CJ. Fato de grande importância, pois o esporte aos adolescentes não é analisado somente como um fator de poder econômico por meio de representar o gosto a competir, agradando todas as classes, principalmente as com menos posses.

Uma análise realizada por Lamenha (2003), com 38 atletas iniciantes no handebol de ambos os sexos em uma capital nordestina, verificou que as instituições públicas demonstram maior motivação intrínseca, e as particulares o contrário. Sendo assim, observou-se que os jogadores de não gostam de perder no esporte e, o praticam como uma forma de lazer, e questões voltadas para meios externos estão mais presentes em jovens de rede privada, supondo-se uma questão de maior nível sócio-econômico com maior aceitação e cobrança por parte de amigos e familiares.

Assim, se pensarmos nas crianças e jovens como um grupo de seres humanos com direitos específicos a suas condições naturais, sendo o aprendizado, a evolução, o desenvolvimento, de presente e de futuro, e até mesmo de sonharem e conquistarem espaço como grandes atletas, entende-se que o esporte pode ser um grande veículo na promoção dos 


\section{HORIZONTES - REVISTA DE EDUCAÇÃO}

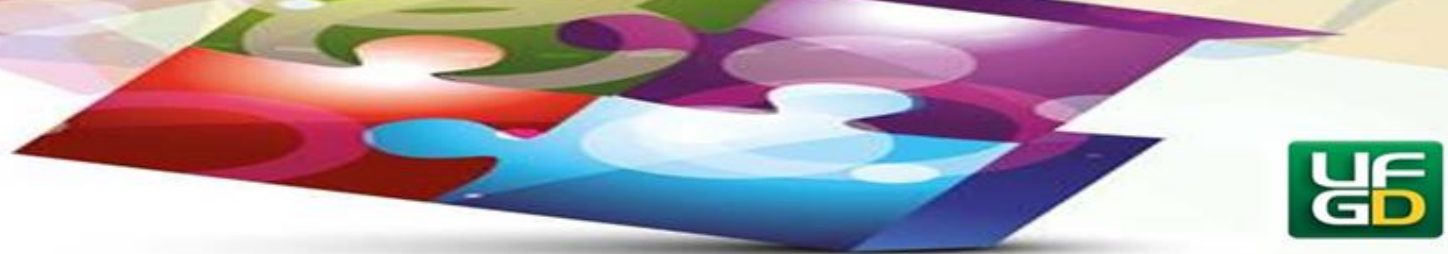

direitos, desde que analisado mais como um direito humano efetivo, um causador de dignidade e felicidade humana, e a que todos têm acesso, sem discriminações nem lugar da habilidade, da dificuldade, da dimensão do corpo ou dentre outras. Ainda veremos que os processos de particularização tem sido um obstáculo à consecução desse direito. Espera-se que, nas próximas décadas, seja possibilitado criar meios para que essa prática possa ser ainda mais um veículo de transmissão de aprendizagens, de tolerância e um caminho para que a humanidade promova cada vez mais a felicidade, a paz e o entendimento entre todos os povos (KNIJNIK; MASSA; FERRETTI, 2008).

Entende-se que, a motivação esportiva na adolescência é fruto de vários fatores, assim, se a estimulação for adequada para o gosto, não gerando traumas perante aquela prática, a utilização do esporte como uma forma de lazer para toda a vida, torna-se mais significativa, pois, as lembranças serão em sua maioria positivas. Da mesma forma, quando se entende os aspectos que mais motivam os jovens a procurarem escolinhas esportivas, possibilita-se a melhor preparação de dirigentes técnicos e escolas para o planejamento visando a diminuição do abandono esportivo, uma vez que a idade adulta influência grandemente a esse acontecimento, pois a vida profissional geralmente se inicia nessa fase da vida, sendo diminuído o tempo disponível para atividades saudáveis no pequeno espaço de tempo destinado ao lazer.

\section{Considerações Finais}

Conclui-se que, o principal motivo que conduz os adolescentes à prática esportiva está ligado a orientação à performance, e o que menos os motiva a competir é voltado à questão do status. Os rapazes são mais motivados no esporte quando comparados às moças.

Não foram encontradas diferenças significativas quanto à classificação econômica e tipo de modalidade, entendendo-se, desse modo, que o poder aquisitivo e fatores intrínsecos e extrínsecos não influenciaram nos motivos à competitividade no esporte dos adolescentes pesquisados, segundo suas concepções.

O presente estudo sugere a realização de novas pesquisas, com uma amostra com idades mais próximas, como por exemplo, de 13 a 14 anos de idade, ou 16 a 17, assim verifica-se os motivos à competitividade de acordo com o passar da idade. 


\section{HORIZONTES - REVISTA DE EDUCAÇÃO}

e-ISSN: 2318-1540

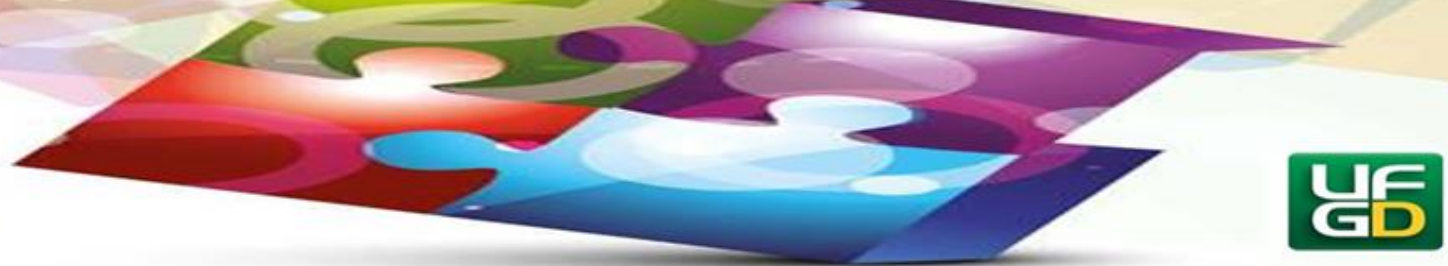

\section{Referências}

ABRAMO, H. W. O uso das noções de adolescência e juventude no contexto brasileiro. In: FREITAS, M. V. (Org.) Juventude e adolescência no Brasil: Referências conceituais. 2 ed. São Paulo: Ação Educativa, 2006.

ASSOCIAÇÃO BRASILEIRA DE EMPRESAS DE PESQUISA (ABEP). CCEB Critério Brasil. 2011. Disponível em: <http://www.abep.org/novo/Content.aspx?ContentID=301>. Acesso em: 23 jul. 2011.

BALBinOtTI, M. A. A; BARBOSA, M. L. L; SALDANHA, R. P; BALBINOTTI, C. A. A. Estudos Fatoriais e de Consistência Interna da Escala Balbinotti de Motivos à Competitividade no Esporte (EBMCE-18). Motriz, Rio Claro, v.17 n.2, abr./jun. 2011.

BRASIL. Estatuto da criança e do adolescente [recurso eletrônico]: Lei n. 8.069, de 13 de julho /de 1990, e legislação correlata. - 14. ed. - Brasília: Câmara dos Deputados, Edições Câmara, 2016a. - (Série legislação; n. 237).

CRATTY, B. J. Psicologia no esporte. 2 ed. Rio de Janeiro: Prentice-Hall do Brasil, 1984.

FARIA, T. G. Análise comparativa do nível de motivação intrínseca de atletas de ambos os sexos, participantes de esportes individuais e coletivos, com diferentes níveis de experiência. Dissertação (Mestrado em Educação Física) Universidade Federal do Paraná, Curitiba, 2004.

GUEDES, D. P; GUEDES, J. E. R. P. Manual prático para avaliação em educação física. 1 ed. Barueri: Manole, 2006.

INTERDONATO, G. C; MIARKA, B; OLIVEIRA, A. R; GORGATTI, M. G. Fatores motivacionais de atletas para a prática esportiva. Motriz, v. 14, n. 1, 2008.

JUCHEM, L. Motivação à prática regular de atividades físicas: um estudo sobre tenistas brasileiros infanto-juvenil. Dissertação (Mestrado em Ciências do Movimento Humano) Universidade Federal do Rio Grande do Sul (UFRGS). Porto Alegre, 2006.

KNIJNIK, J.D; MASSA, M; FERRETTI, M. A. C. Direitos Humanos e Especialização Esportiva Precoce: Considerações Metodológicas e Filosóficas. In: MACHADO, A. A. (Org.) Especialização Esportiva Precoce: Perspectivas atuais da Psicologia do Esporte. Jundiaí: Fontoura, 2008.

LAMENHA, I. C. B. Motivação no handebol em desportistas iniciantes. Dissertação (Mestrado em Psicologia Escolar) Pontífica Universidade Católica (PUC). Campinas, 2003.

LOPES, P; NUNOMURA, M. Motivação para a prática e permanência na ginástica artística de alto nível. Rev. bras. Educ. Fís. Esp., v.21, n³, 2007. 


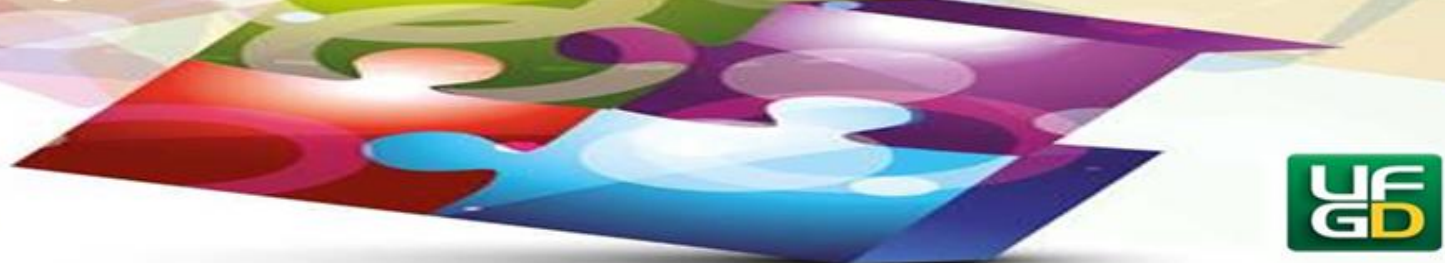

PAIM, M. C. C. Fatores motivacionais e desempenho no futebol. Rev. de Educ. Fís./UEM, v. $12, \mathrm{n}^{\circ} 2,2001$.

SAMULSKI, D. Psicologia do esporte: Conceitos e novas perspectivas. Barueri: Manole, 2009.

SIMÕES, A. C; BÖHME, M. T. S; LUCATO, S. A Participação dos Pais na Vida Esportiva dos Filhos. Rev. paul. Educ. Fís., v.13, nº1, 1999.

THOMAS, J. R.; NELSON, J. K. Métodos de Pesquisa em Atividade Física. 3 ed. Porto Alegre: Artmed, 2002.

WATARAI, F; ROMANELLI, G. Trabalho e identidade de adolescentes do sexo masculino de camadas populares. In: Simpósio Internacional do Adolescente, São Paulo, 2005.

WILMORE, J. H; COSTILL, W; KENNEY, L. Fisiologia do esporte e do exercício. 1 ed. Barueri: Manole, 2010.

Enviado: $13 / 08 / 2018$

Aceito: $26 / 09 / 2018$ 